\title{
水平円柱内固相の接触融解過程
}

\author{
根本寛幸(茨大) ${ }^{\circ}$, 小木浩通（茨大）,椎名保顕（原子力機構）,稲垣照美（茨大）
}

\section{Close Contact Melting of Solid in a Horizontal Cylindrical Capsule}

\author{
Hiroyuki NEMOTO, Hiromichi OGI, Yasuaki SHIINA and Terumi INAGAKI
}

Closed contact melting of solid phase change material (solid PCM) in a horizontal circular cylinder under constant heat transfer coefficient was investigated by an experiment and an analysis. Solid PCM of water and teradecane filled in an acrylic and a copper circular cylinder was melted by natural and forced convection. Melting velocity measured by visualized solid liquid boundary increased with time under the constant heat transfer coefficient. This agrees with the analysis. Observation of the solid liquid boundary shows that for case of the melting in the copper cylinder, solid phase is melted mainly by contact heat transfer, but effect of natural convection can not be ignored for case of the melting in the acrylic cylinder.

Keywords: Close contact melting, Horizontal circular cylinder, Forced convection, PCM

\section{1. はじめに}

固相と伝熱面が非常に薄い液層を介して接触する接 触融解は高い熱伝達特性を示すことが報告されている(1)。 近年エネルギー有効利用のために注目されている潜熱蓄 熱では、その実用化に相変化時の伝熱促進が重要とされ て扣り、固相と液相の密度差により生じるこの接触融解 を利用することにより伝熱促進を図ることが可能である。 一方、潜熱蓄熱の伝熱促進の方法として、蓄熱媒体(PCM) 中に発泡金属を含浸させ実効熱伝導率を高くすることが 検討され、放熱時の伝熱促進には極めて有効であること が示されている ${ }^{(2)}$ が、この方法は融解時には接触融解を 利用することができないため、蓄熱・放熱時を含めた総 合的な伝熱促進の有効性の評価を行うには、潜熱蓄熱技 術における接触融解の評価が必要である。従来の接触融 解の研究は、その多くは伝熱面が等温の場合に限られて きた ${ }^{(3)}$ 。しかし、実際の蓄熱・放熱過程では伝熱面は等 温ではなく、熱伝達率一定と考えられるため、その場合 の接触融解特性を明らかにする必要がある。本研究では、 相変化時の熱抵抗低減に有効であるカプセル型潜熱蓄熱 方式に着目し、伝熱流体中に水平円柱潜熱蓄熱カプセル がおかれた場合の接触融解特性を実験及び解析により調 心、両者の比較をするとともに、固液相変化界面形状を 可視化・観察して接触融解を調べたので報告する。

\section{2. 実験装置及び寒験方法}

Fig.1 に実験装置の概略図を示す。Fig.1(a)は強制対流 融解実験用の空気流路及び自然対流融解実験用のアクリ ル製箱を示す。強制対流試験部は断面 $100 \mathrm{~mm} \times 100 \mathrm{~mm}$, 長さ $1000 \mathrm{~mm}$ ，アクリル箱は $400 \mathrm{~mm} \times 300 \mathrm{~mm} \times 300 \mathrm{~mm}$ で ある。また、Fig.1(b)は円柱カプセルの模式図を示す。円 柱カプセルとして外径 $40 \mathrm{~mm}$ 、内径 $36 \mathrm{~mm}$ のアクリル円 柱及び外径 $40 \mathrm{~mm}$ ，内径 $38 \mathrm{~mm}$ の銅円柱を用いた。両円 柱とも長さは $110 \mathrm{~mm}$ である。円柱カプセルには、内面 上部及び下部に深さ約 $0.3 \mathrm{~mm}$ の矩形溝を中央から端部

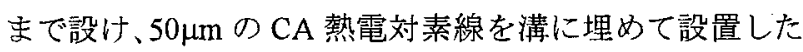
(Fig.1(b)参照)。円柱カプセル外側には、内面熱電対の外
側及び 90 度おきに $50 \mu \mathrm{m}$ の CA熱電対素線を取り付けた。 PCM として、水とテトラデカンを用いた。テトラデカン の物性值を Table 1 に示す。アクリル及び銅円柱カプセル の両端は、固液相変化界面形状の可視化のため厚さ $8 \mathrm{~mm}$ のガラス栓で蓋をした。片側のガラス栓に、液注入用お よび空気抜き用の穴を取り付け、SUS パイプにどニール チューブを取り付けた。空気抜き用チューブは、円柱内 に満たした PCM が凝固・融解により体積変化を生じる ため、体積調節用としても用いた。

実験は以下のようにして行った。PCMを満たした円筒 カプセルを、低温循環水槽に入れて凝固させる。凝固し

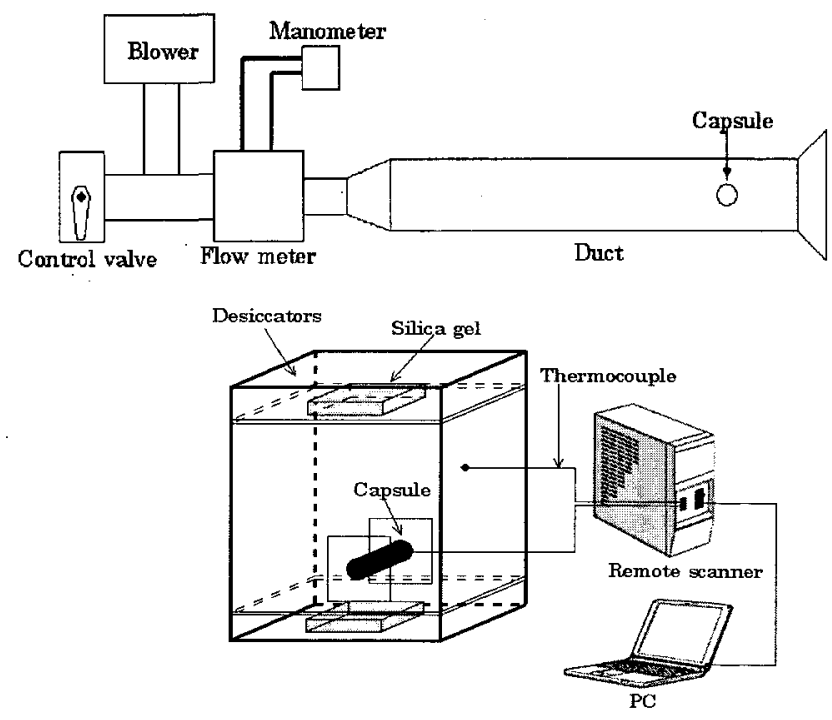

(a) Experimental apparatus for forced convection

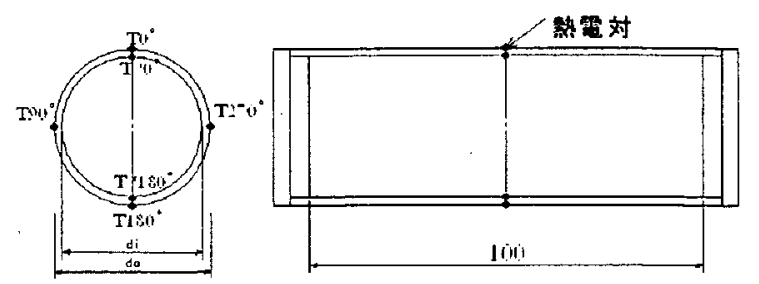

(b)Configuration of a circular cylindrical capsule Fig.1 Outline of experimental apparatus 


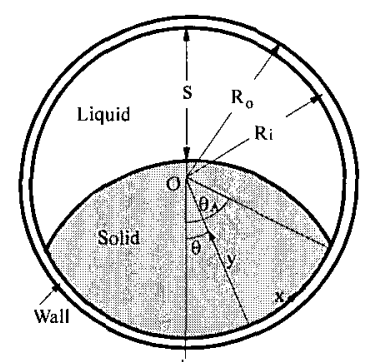

Fig.2 Physical coordinate of a capsule

Table 1 Thermal properties of Tetradecane

\begin{tabular}{|l|c|l|l|l|}
\hline$T_{f}\left({ }^{\circ} \mathrm{C}\right)$ & $\rho\left(\mathrm{g} / \mathrm{cm}^{3}\right)$ & $C_{p}(\mathrm{~J} / \mathrm{gK})$ & $\lambda(\mathrm{W} / \mathrm{mK})$ & $L(J / \mathrm{g})$ \\
\hline \multirow{2}{*}{5.9} & $0.81(\mathrm{~s})$ & $1.8(\mathrm{~s})$ & $0.43(\mathrm{~s})$ & \multirow{2}{*}{229} \\
\cline { 2 - 4 } & $0.77(\mathrm{l})$ & $2.1(1)$ & $0.14(1)$ & \\
\hline
\end{tabular}

て一定温度に保たれた円柱カプセルを取り出し、強制対 流試験部または自然対流用アクリル箱内に設置し

(Fig.1(a)参照)、融解実験を開始する。円柱表面温度の 時間変化を PC により収録するとともに、円柱カプセル 端部から光を当て、一定時間おきにビデオにより撮影を 行う。実験終了後、ビデオ写真の固液界面位置を計測し て固相の融解速度を求めた。

融解実験注自然対流及び強制対流条件下で行った。強 制対流実験のレイノルズ数は約 400 及び 3200 である。

\section{3. 解析}

Fig.2 に解析の座標系を示す。椎名らは、円柱カプセル 外表面の熱伝達率一定の条件で、円柱内面から PCM の熱入力は、円柱カプセル内面と固相の「接触面」のみ で生じるという仮定の下に接触融解の解析を行い、以下 の結果を得ている(4)。

$\frac{d \xi}{d \tau}=\left(\frac{5}{192}\right)^{0.25} \frac{\left(A r \cdot \mathrm{Pr}^{0}\right)^{0.25}}{S t e} G^{0.75}\left\{\frac{3 \cos ^{-1} \xi-3 \xi \sqrt{1-\xi^{2}}}{\sqrt{1-\xi^{2}}\left(-3 \xi^{4}+\xi^{2}+2\right)}\right\}^{0.25}$

ここで $\xi=s / 2 R_{i}, \tau=F o \cdot S t e, F o=\kappa t / R_{i}^{2}$, Ste $=C_{p}\left(T_{\infty}-T_{f}\right) / L$, $A r=g R_{i}^{3}\left|\rho_{s}-\rho_{l}\right| / v^{2} \rho_{l}$ であり、 $\mathrm{s}$ は固相上面（水の場合下 面）と円柱上面（水の場合円柱下面）との距離、 $R_{i}$ 注円 柱カプセル内半径である。また、融解による固相の沈下 （水の場合は浮上）速度を $V_{0}$ とすると、固相と伝熱面の 隙間 $\delta$ は $\delta=\kappa G / V_{0}: \cos \theta$ と与えることができ、G は次式 で与えられる。

$2 G^{2}+G\left(20+3 S t e+\frac{7 \operatorname{Re} \operatorname{Pr} \sin \theta_{A}}{\pi B_{i e}}\right)-20 S t e+\frac{20 \operatorname{Re} \operatorname{Pr} \sin \theta_{A}}{\pi B_{i e}}=0$

ここで、 $\theta_{A}$ は固相と円柱が接する最大角度である (Fig.2 参照)。Bi $i_{e}$ は円柱内面の熱通過率を用いたビオ一数であ る。(1)式を積分することにより $゙$ の時間変化が得られる が、Ste〈〈1の場合には次式が得られる。

$$
d \xi / d t=\pi B_{i e} \cdot S t e v / 2 \operatorname{Pr} R_{i}^{2} \sqrt{1-\xi^{2}}
$$

これを積分して次式を得る。

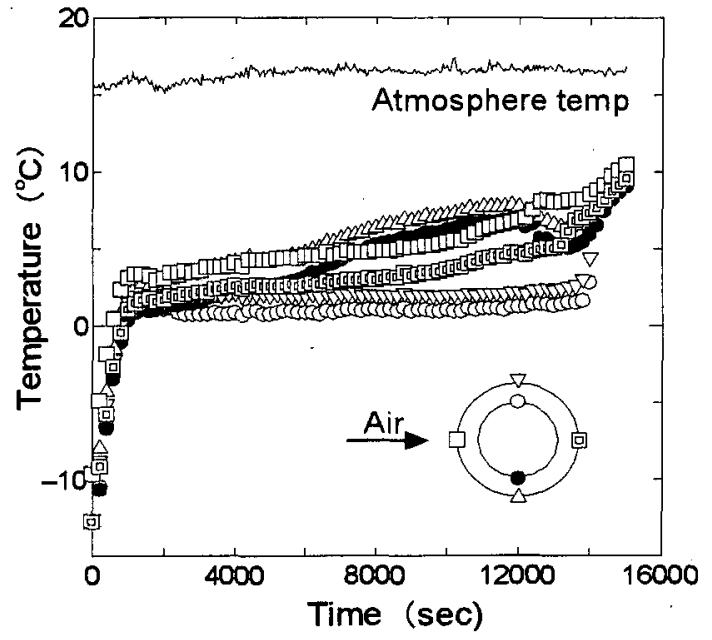

(a) Acrylic cylindrical capsule

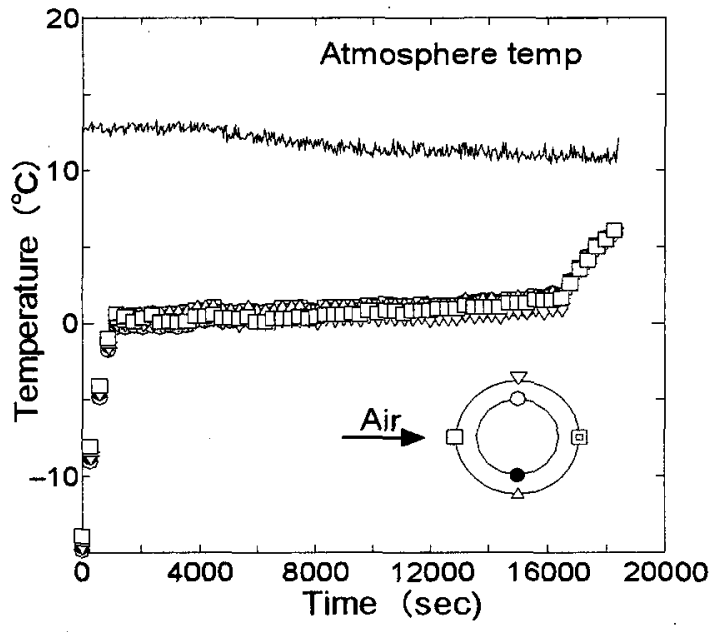

(b) Cooper cylindrical capsule

Fig. 3 Time traces of temperatures during melting at $\mathrm{Re}=400$ for water as PCM

$$
\xi \sqrt{1-\xi^{2}}+\sin ^{-1} \xi=\pi B_{i e} \cdot \text { Ste } \tau
$$

$S t e\left\langle 1\right.$ の場合、融解終了時間 $t_{e}$ は以下のようになる。

$$
\tau_{e}=1 / 2 B_{i e} \cdot \text { Ste }
$$

\section{4. 結果と考察}

4.1 伝熱実験結果 Fig. 3 に $\mathrm{PCM}=$ 水、 $\mathrm{Re}=400$ の場合の 円柱温度の時間変化を示す。Fig.3(a)はアクリル円柱、(b) は銅円柱の場合の結果である。氷の融解が始まると、水 は浮上するため、Fig.3(a)に示されるように、アクリル円 柱の場合には円柱上部温度は低温に保たれ、下部温度は 逆に上昇する。アクリル円柱の場合、表面温度はばらつ きながら、時間とともに上昇している。 $\mathrm{Re}=400$ の場合、 よどみ点熱伝達率は 90 度離れた上下面の熱伝達率より 約 2 倍高くなる( ${ }^{(5)}$ が、水の浮上により、円柱下部の温度 は 6000 秒以降でよどみ点よりも高くなることが示され ている。図には融解完了の近くで円柱下部温度が低下す るのが見られるが、これは融解による水の体積収縮に伴 い、空気抜きチューブ内に保持した水が内部に流入し、 低温液が円柱下部に降下したことにより生じたと考えら れる。銅円柱の場合には、Fig.3(b)に示すように融解完了 までの間、銅表面温度のばらつきは非常に小さく、温度 


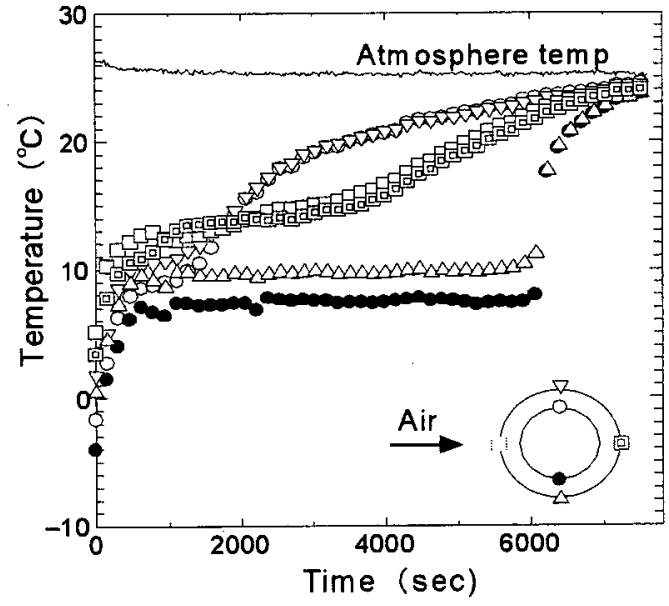

(a) Acrylic cylindrical capsule

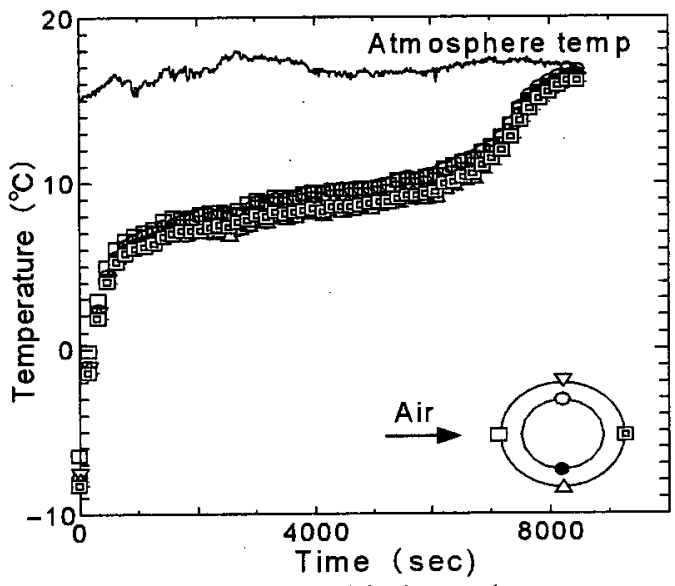

(b) Cooper cylindrical capsule

Fig.4 Time traces of temperatures during melting at $\mathrm{Re}=3200$ for tetradecane as PCM

も時間とともに徐々に上昇するものの、融点近傍に保持 されることがわかる。

Fig.4に $\mathrm{PCM}=$ テトラデカン、Re=3200の場合の結果を 示す。Fig.4(a)(b)は、それぞれ、アクリル円柱及び銅円柱 の結果を示したものである。テトラデカンの場合は融解 に伴い固相は沈下するため、アクリル円柱の場合には Fig.4(a)に示すように円柱.上部温度が上昇し、よどみ点温 度より高くなるのが見られる。また、円柱下部の内外表 面温度差に比へ、上部の内外面表面温度差は非常に小さ くなっている。これから、固相が「接触」しない上部表 面から液相一の熱の流入は非常に小さいと考元られる。

一方、Fig.3(a)の場合には、内外表面温度差は固相が「接 触」なない面においても上面と同程度大きいことから、 下面からの熱流入量注「接触面 (上面)」からの熱流入量 と比較して無視し得ないと考えられる。Fig.4(b)に示す銅 円柱の場合には、よどみ点及び上部円柱温度が高温を示 すものの、Fig.3(a)と同様に表面温度のばらつきは小さく、 時間とともに温度が上昇しているのが観察される。

4.2 融解速度 固液界面のビデオ写真から s を測定して、 固相の移動速度を測定した。 $\mathrm{Re}=3200, \mathrm{PCM}=$ 水の場合の $\xi=s / 2 R_{i}$ と $t / t_{e}$ の関倸を Fig. 5 に示す。図で破線及び実
線は(1)式を積分して得られた解析結果であり、点線は円 柱カプセル表面温度が一定の場合の解析結果 ${ }^{(3)}$ である。 また、記号は銅円柱及びアクリル円柱の実験結果である。 図よりわかるとおり、壁温が一定の場合には、 $\xi$ と $t / t_{e}$ の 関係は上に凸となるが、熱伝達率一定の場合には下に凸 となる。すなわち、等温の場合には融解初期に融解速度 が大きく、次第に融解速度が小さくなるのに対して、熱 伝達率一定の場合には、融解初期には融解速度が小さく、 次第に大きくなる。実験と解析結果は比較的良い一致を 示している。

融解速度 $\boldsymbol{d} \xi / \boldsymbol{d} \boldsymbol{t}$ と $\boldsymbol{t} / \boldsymbol{t}_{\boldsymbol{e}}$ の関係を Fig.6に示す。図は PCM が水の場合で、 $\mathrm{Re}=3200$ と 400 の場合の結果を示したも のである。図で丸記号と実線及び三角記号と点線は、そ れぞれアクリル円柱及び銅円柱の場合を示し、記号は実 験結果を、線は解析結果を示す。また、黒記号及び白抜 き記号はそれぞれ $\mathrm{Re}=400$ および 3200 の場合を示す。

実験結果は、ばらつきはあるものの解析結果と比較的良 い一致を示し、時間の経過とともに融解速度が増加する 傾向を示している。また、 $\mathrm{Re}=400$ の場合、解析結果では アクリル円柱の方が銅円柱に比べて融解速度が大きくな

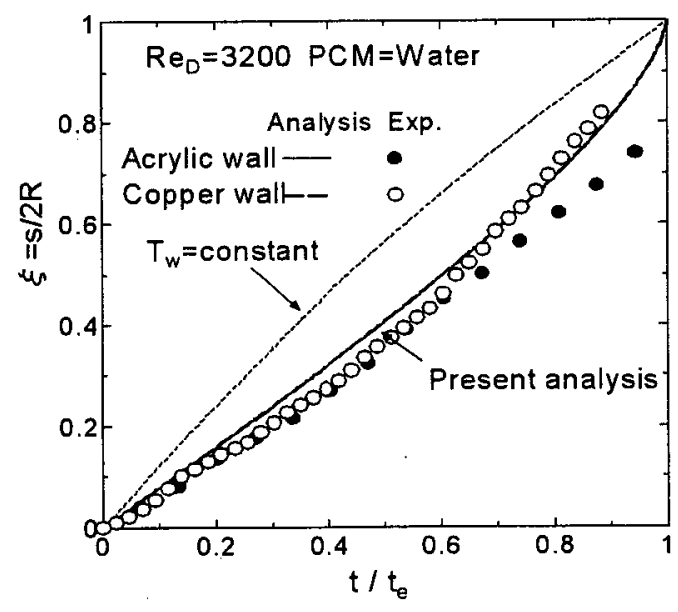

Fig. 5 Plot of $\mathrm{s} / 2 \mathrm{R}_{\mathrm{i}}$ against non-dimensional melting time

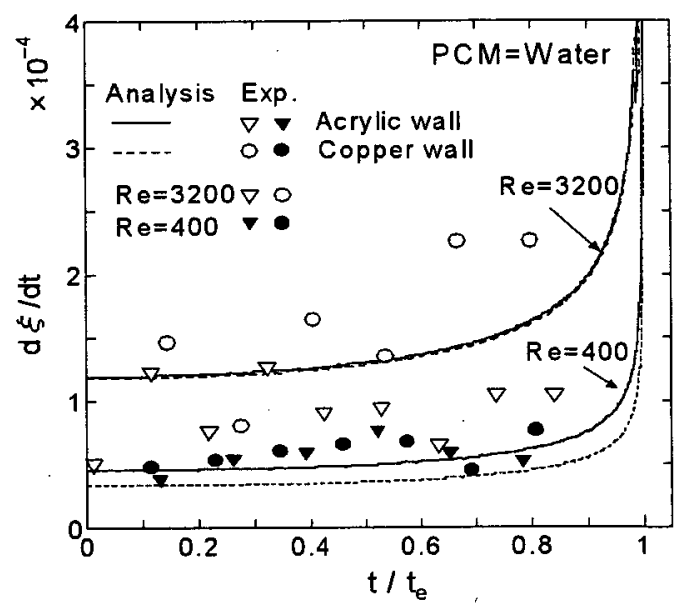

Fig.6 Plot of melting velocity against non-dimensional melting time 
ることが示されているが、これは、アクリル円柱を用い た実験時の空気温度が、銅円柱を用いた実験時よりかな り高かったことによるものである (Fig.3 参照)。

\section{3 固液界面形状の可視化}

$\mathrm{Re}=3200$ の場合における固液界面形状を Figs.7,8 に示 す。Fig.7 は PCM としてテトラデカンを、Fig.8 は水を用 いた場合の結果である。それぞれの図の(a)はアクリル円 柱を、(b)は銅円柱の場合を示す。Fig.7 から、銅円柱の 場合（Fig.7(b)）には, 固相上部の形状が円柱内面上部形 状とほぼ相似形になる、すなわち固相上面の曲率半径が の場合には、固相上部の曲率半径は $\boldsymbol{R}_{\boldsymbol{i}}$ と比べて小さくな 上面からの融解は少ないが、アクリル円柱の場合には、 固相上面側においても、特に円柱内面と近接する領域に

Fig.8 は水の場合の結果であるが、この場合もテトラデ カンの場合と同様の現象が観察される。アクリル円柱は 銅円柱に比べて熱伝導率は非常に低いにもかかわらず、 銅円柱と同程度の融解速度を示している(Fig.6 参照)が、 円柱内半径 $\boldsymbol{R}_{i}$ にほぼ等しくなるのに対し、アクリル円柱 ることが観察される。これは、銅円柱の場合には、固相 おいて融解が大きいことを示すと考えられる。

これは、内部自然対流の影響によると考えられる。円柱 カプセル内の接触融解に及ぼす内部自然対流の影響は今 後の研究課題である。

\section{5. 結論}

熱伝達率一定の場合の水平円柱カプセル内相変化物質の 接触融解の研究を行い、以下の結論を得た。

1 、融解速度は等温の場合とは異なり、時間の経過とと もに増加する。

2. 銅円柱の場合の融解は主に「接触面」で生じるが、 アクリル円柱の場合には「接触面」以外における融 解を考慮する必要がある。

3. 融解速度の理論と実験は比較的良く一致する。

[記号] $\mathrm{Bi}_{\mathrm{e}}$ : ビオー数 $=h_{e f} R_{i} / \lambda, \mathrm{C}_{\mathrm{p}}$ : 比熱, $\mathrm{g}$ : 重力加速度, $\mathrm{h}_{\mathrm{w}}$ : 表面

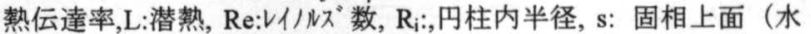
の場合下面）と円柱上面（水の場合円柱下面）との距離, Ste:怀 7ア'数, $\mathrm{t}$ : 時間,, $\mathrm{t}_{\mathrm{e}}$ : 融解終了時間, $\mathrm{T}_{\mathrm{f}}$ : 融点, $\mathrm{T}_{\infty}$ : 外部流体温度, $\rho$ : 密度, $\lambda$ : 熱伝導率,, $\mathrm{k}$ :温度拡散率 [subscript]1:液相,s:固相, <参考文献〉

(1) Moallemi.M.M.et al.,Trans.ASME.C.,108,pp.894-899(1986) (2) SHIINA.Y. et al., Int.J.Heat Mass Transfer, 48,pp.373-383(2005)

(3) Bahrami,P.A. et al., Trans.ASME.C., 109, pp.806-809(1987) (4)椎名保顕他、第 43 回日本伝熱シンポジウム予稿集 D224(2006)

(5)Eckert,E.R, Trans.ASME.74,pp.343-347(1952)

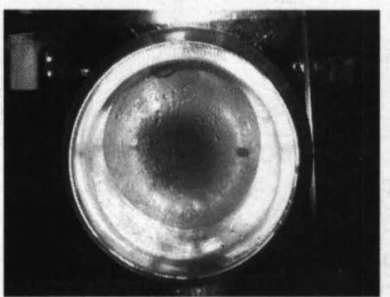

$\mathrm{t}=3000 \mathrm{sec}$

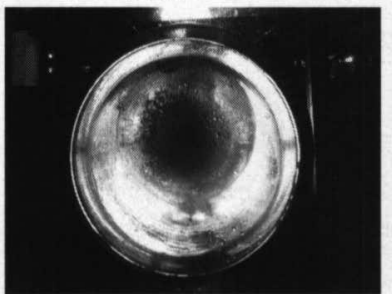

$\mathrm{t}=4200 \mathrm{sec}$

(a) Acrylic cylindrical capsule

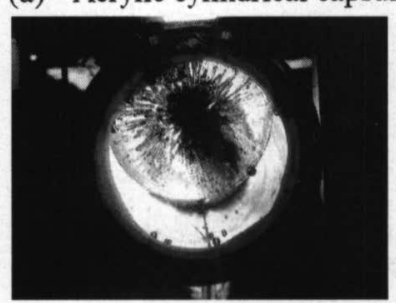

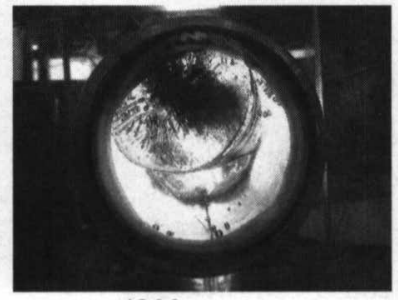

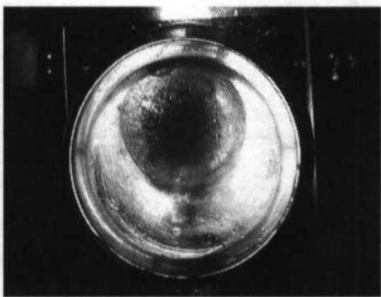

$\mathrm{t}=5400 \mathrm{sec}$

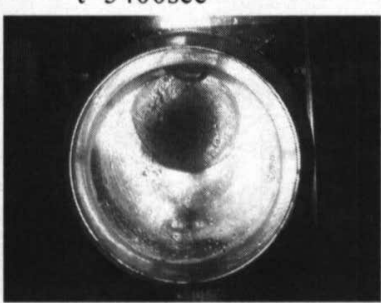

$\mathrm{t}=6600 \mathrm{sec}$ (a) Acrylic cylindrical capsule

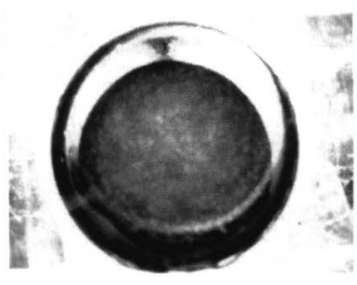

$\mathrm{t}=2400 \mathrm{sec}$

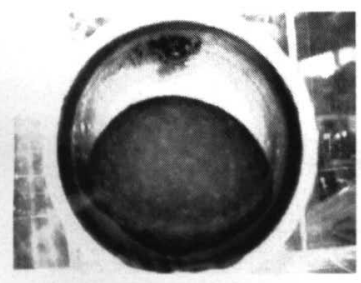

$\mathrm{t}=3600 \mathrm{sec}$

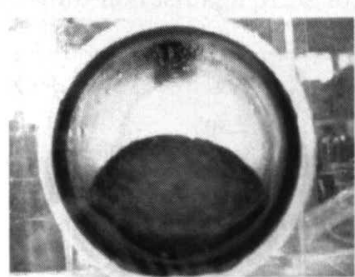

$\mathrm{t}=4800 \mathrm{sec}$

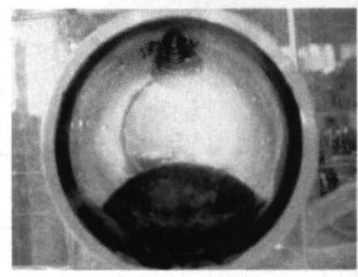

$\mathrm{t}=6000 \mathrm{sec}$ (b) Copper cylindrical capsule

Fig. 7 Solid liquid boundary for $\mathrm{Re}=3200$ (PCM=tetradecane) $\mathrm{t}=3300 \mathrm{sec}$

$\mathrm{t}=4200 \mathrm{sec}$

(b) Copper cylindrical capsule

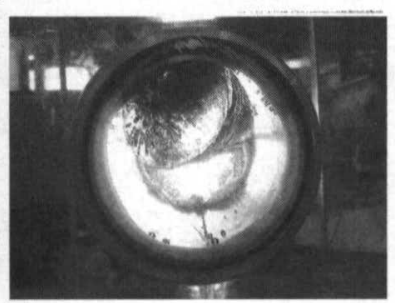

$\mathrm{t}=5100 \mathrm{sec}$

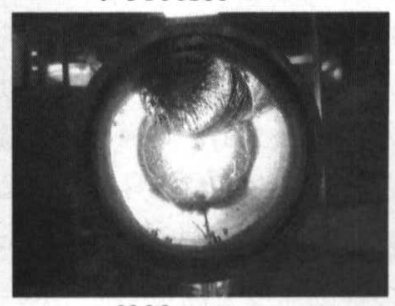

$\mathrm{t}=6000 \mathrm{sec}$
Fig. 8 Solid liquid boundary for $\mathrm{Re}=3200$ (PCM=water) 